\title{
Análise morfométrica das bacias de captação das cachoeiras do município de Pelotas (Rio Grande do Sul - Brasil): subsídios para ações de geoconservação
}

\author{
Morphometric analysis of waterfalls catchments in Pelotas \\ municipality (Rio Grande do Sul- Brazil): subsidies for \\ geoconservation actions
}

Adriano Luis Heck Simon, Laboratório de Estudos Aplicados em Geografia Física, Departamento de Geografia, Universidade Federal de Pelotas, Brasil, adrianosimon@gmail.com

(1) https://orcid.org/0000-0003-2888-308X

Kelvin Dutra Xavier, Laboratório de Estudos Aplicados em Geografia Física, Programa de Pósgraduação em Geografia, Universidade Federal de Pelotas, Brasil, kelvin.xavier@hotmail.com

(iD) https://orcid.org/0000-0003-4590-1876

Victória Dejan Paganotto, Laboratório de Estudos Aplicados em Geografia Física, Universidade Federal de Pelotas, Brasil, vic_paganotto@hotmail.com

(1D) https://orcid.org/0000-0002-5713-5817

Cassiely da Roza Pacheco, Laboratório de Estudos Aplicados em Geografia Física, Universidade Federal de Pelotas, Brasil, pachecocassiely@gmail.com

(1) https://orcid.org/0000-0002-2705-1030

Resumo: $O$ trabalho tem como objetivo identificar e analisar as características morfométricas das bacias de captação das cachoeiras do Arco-Íris, Imigrante e Paraíso, localizadas no município de Pelotas (Brasil), visando estratégias de geoconservação e promoção dessas feições geopatrimoniais com evidente valor intrínseco e reconhecido valor turístico. A metodologia proposta abrangeu: (a) a delimitação das bacias de captação das três cachoeiras, (b) a identificação e análise da energia do relevo e de outros parâmetros morfométricos elementares e, (c) trabalhos de campo para coleta dos pontos de localização das cachoeiras e verificação dos resultados. A análise dos parâmetros morfométricos possibilitou a identificação e compreensão de potencialidades e limitações das bacias de captação que drenam para as cachoeiras, indicando áreas e condições de atuação dos processos morfogenéticos que comprometem a integridade da bacia hidrográfica e, por consequência, podem atuar na estrutura e dinâmica das cachoeiras sob pesquisa. Neste sentido, a partir destes dados, é possível realizar propostas e estratégias de geoconservação das bacias de captação, uma vez que as cachoeiras estudadas são reconhecidas enquanto geopatrimônio do município de Pelotas e precisam ser preservadas em decorrência de seus valores intrínsecos, econômicos e turísticos.

Palavras-chave: Geodiversidade; Geopatrimônio; Patrimônio Geomorfológico; Bacia Hidrográfica.

Abstract: The present work is aimed to identify and analyze the morphometric characteristics of the Arco-Íris, Imigrante and Paraíso waterfalls catchments (located in Pelotas municipality, state of Rio Grande do Sul - Brazil) aiming at geoconservation strategies and promotion of these geoheritage features with an evident intrinsic value and acknowledged touristic value. The proposed methodology comprised the following: (a) the delimitation of the catchment of all three waterfalls; (b) the identification and analysis of the energy of relief for the catchment of these waterfalls and, (c) field works for the location points of the waterfalls and to check the results. The analysis of the morphometric parameters enabled the identification and the understanding of the potentials and limitations of catchments that drain into the waterfalls, indicating areas and conditions of action of morphogenetic processes that undermine the integrity of the river basin and, therefore, may act in the structure and in the dynamics of the waterfalls under research. In this sense, based on this data, it is possible to make proposals and develop strategies of geoconservation of the catchments as the waterfalls studied are acknowledged as 
a heritage of the city of Pelotas and need to be preserved due to their intrinsic, economic and touristic values.

Keywords: Geodiversity; Geoheritage; Geomorphological Heritage; River Basin.

\section{Introdução}

A geodiversidade abarca a variedade geológica de minerais, solos, sedimentos, rochas, feições geomorfológicas e processos físicos que compõem a paisagem (Gray, 2004; Brilha, 2005). Estes elementos podem ser interpretados em diferentes escalas, desde a escala microscópica ou grande escala (minerais e sedimentos), à pequena escala (formações rochosas, feições geomorfológicas e sistemas de bacias hidrográficas) (Jorge, Guerra, 2016).

Existem valores que asseguram a promoção da geodiversidade, pois a paisagem exibe diversos valores passíveis de evidência e que apresentam uma necessidade de promoção e conservação (Sharples, 2002; Brilha, 2005). Uma vez que é atribuído algum valor a geodiversidade - identificados a partir de uma inventariação quantitativa e qualitativa - os elementos serão considerados como geopatrimônio e demandarão estratégias de geoconservação em decorrência deste valor (Borba, 2011).

O geopatrimônio compreende uma parcela da geodiversidade cujas características se destacam em função de seus valores, podendo ser classificado em patrimônio hídrico, geológico, pedológico e geomorfológico (Sharples, 2002; Silva, Aquino, 2018). O patrimônio geomorfológico corresponde às feições que apresentam a história do relevo e sua constante evolução, já que as formas do relevo auxiliam na formação e sustentação da paisagem (Rodrigues, Fonseca, 2008). Brilha (2005) explica que o geopatrimônio corresponde aos locais com excepcional valor científico, cultural ou turístico, considerando suas formas de relevo isoladamente ou em conjunto como significativas para a manutenção de processos morfogenéticos ocorridos em uma dada região (Von Ahn, 2018).

No município de Pelotas (estado do Rio Grande do Sul - Brasil) ocorrem cachoeiras (Figura 1) que, mesmo não sendo reconhecidas como geossítios ou geomorfossítios, podem ser compreendidas como parte do geopatrimônio pelo seu valor intrínseco, ou seja, por possuírem importância estética, paisagística, econômica e turística devido à sua própria ocorrência na natureza, oriunda da interação sistêmica entre elementos da geodiversidade como a água, as rochas e o relevo (Bento, Rodrigues, 2010).

As cachoeiras recebem, constantemente, matéria e energia derivadas de uma bacia de captação onde se articulam, no tempo e no espaço, os elementos físico-ambientais e socioeconomicos. Desta forma, qualquer modificação no recebimento ou na liberação de matéria no interior de uma bacia de captação que drena para uma cachoeira, tende a realizar uma mudança compensatória a fim de minimizar os efeitos das modificações e de restaurar o equilíbrio dinâmico (Lima, Lakia, 2000 apud. Teodoro et al., 2007). 

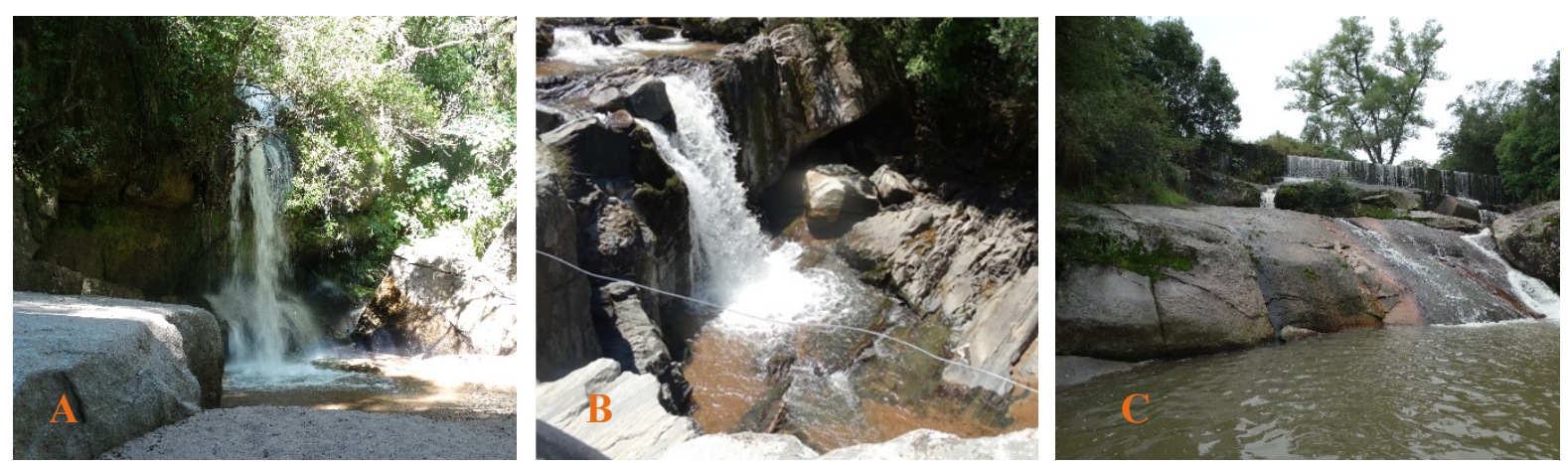

Figura 1: A) cachoeira Arco-Íris; B) cachoeira Imigrante; C) cachoeira Paraíso.

Fonte: Autores.

As bacias de captação das cachoeiras em estudo encontram-se inseridas na zona sob influência do Escudo Sul-Riograndese. A cachoeira Arco-íris encontra-se sob cinco unidades geológicas: o Granito Arroio Moinho, o Complexo Granítico Gnáissico Pinheiro Machado, as Fácies sieno-stocks e os Granitóides sin a tardicinemáticos 1 e 2. A bacia da cachoeira Imigrante insere-se em três unidades geológicas: Granito Arroio Moinho, Complexo Granítico Gnáissico Pinheiro Machado e Fácies Sienogranito-stocks. A cachoeira Paraíso encontra-se sob duas unidades geológicas: Granito Arroio Moinho, Complexo Granítico Gnáissico Pinheiro Machado (CPRM, 2019).

Deste modo, se faz necessário um reconhecimento, caracterização e avaliação das ameaças, não apenas da cachoeira em si, mas de sua bacia de captação também, tendo em vista que fenômenos ocorridos ao longo da bacia terão impacto em seu exutório e em pontos específicos, como níveis de base locais, caracterizados pelas cachoeiras.

Neste contexto, para fins de análise ambiental, a bacia hidrográfica propicia o reconhecimento da dinâmica ocupacional e geomorfológica que ocorre em seu interior, constituindo-se como uma unidade de estudo importante para a geomorfologia (Spanghero et al., 2015). Para a compreensão das bacias hidrográficas, os parâmetros morfométricos têm sido utilizados como instrumentos de análise, pois os mesmos auxiliam na identificação e na quantificação de áreas propensas aos processos morfogenéticos que ocorrem no interior das áreas estudadas (Cunha et al., 2003, apud. Boin et al., 2014).

A energia do relevo é um documento cartográfico síntese, resultante da integração de parâmetros morfométricos referentes à dissecação vertical, dissecação horizontal e declividade. Ferreira (2015) destaca que a carta de energia do relevo possibilita mensurar o potencial de acúmulo de energia e a capacidade de erosão, deposição e infiltração em bacias hidrográficas. Salienta-se que a compreensão das condições morfométricas da bacia de captação de uma cachoeira proporciona o entendimento, o planejamento e o ordenamento da dinâmica de ocupação territorial, que, como consequência, subsidia estratégias de preservação e de geoconservação. 
Neste sentido, o presente trabalho tem como objetivo identificar e analisar as características morfométricas das bacias de captação das cachoeiras do Arco-íris, Imigrante e Paraíso, visando estratégias de geoconservação, planejamento ambiental e promoção dessas feições geopatrimoniais com evidente valor intrínseco e reconhecido valor turístico.

\section{Metodologia}

As bacias de captação das cachoeiras do Arco-Íris, Imigrante e Paraíso se encontram localizadas na bacia hidrográfica do Arroio Pelotas, no município de Pelotas e em parte do município de Canguçu, Estado do Rio Grande do Sul (Figura 2). As mesmas se localizam em propriedades rurais onde são aproveitadas economicamente para atividades de lazer e turismo, sobretudo nos meses de verão.

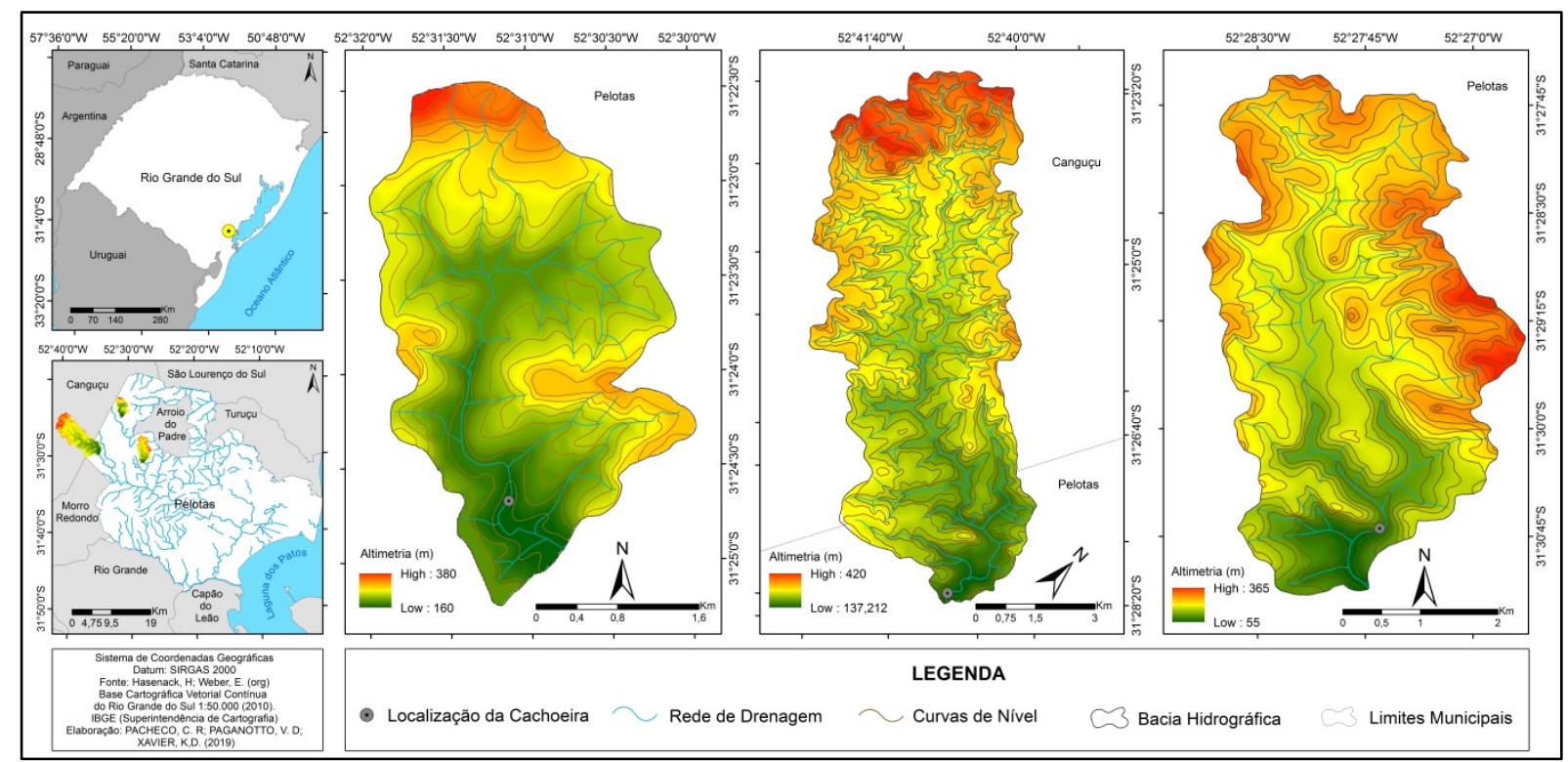

Figura 2: Mapa de localização das bacias de captação das cachoeiras do Arco-íris, Imigrante e Paraíso.

Fonte: Autores.

Para atender ao objetivo proposto, primeiramente foi organizada a base cartográfica das bacias de captação em estudo. Nessa base foram identificadas as cachoeiras reconhecidas turisticamente pela comunidade local e regional, para então, a partir do ponto de localização das mesmas, realizar a delimitação das bacias de captação em ambiente SIG, com o auxílio do software ArcGis 10.2. (Licenciado pelo Laboratório de Estudos Aplicados em Geografia Física-UFPEL).

Para a delimitação das bacias de captação das cachoeiras foi necessária a elaboração de um banco de dados que englobasse os vetores relativos aos pontos cotados, curvas de nível e da rede de drenagem, oriunda da Base Cartográfica Vetorial Contínua do Rio Grande do Sul, disponibilizada por Hasenack e Weber (2010), na escala de 1:50.000. Posteriormente, foi realizado o enriquecimento da rede de drenagem de cada bacia de captação e a delimitação de cada sub-bacia que drena 
para os canais de drenagem. Estas duas últimas etapas foram fundamentais para a elaboração dos mapas de dissecação vertical e dissecação horizontal.

Em um segundo momento foram obtidos alguns parâmetros morfométricos elementares para a compreensão das características das bacias de captação das cachoeiras: o índice de circularidade, a densidade hidrográfica e a densidade de rios. O índice de circularidade expressa o nível de escoamento que contribui para a concentração das águas que possibilitam as cheias (Lana et al., 2001). Os resultados foram obtidos a partir dos valores $\mathrm{em}^{\mathrm{km}}$ da área total da bacia hidrográfica e da área de um círculo com perímetro igual o da área total da bacia hidrográfica. A obtenção deste índice ocorreu por meio da aplicação da seguinte equação:

$$
\text { Ic }=\frac{A}{A c}
$$

A densidade hidrográfica expressa a capacidade da rede hidrográfica em gerar novos cursos d'água (Lana et al., 2001). Para o cálculo da densidade hidrográfica foi aplicada a seguinte equação:

$$
D h=\frac{n}{A}
$$

A densidade de drenagem, por sua vez, indica a velocidade com que a água percorre a bacia hidrográfica e a eficiência da rede de drenagem na bacia hidrográfica (Lana et al., 2001). A mesma é obtida a partir da equação:

$$
D d=\frac{C}{A}
$$

Em um terceiro momento, foram obtidas informações referentes à dissecação vertical, dissecação horizontal e declividade para cada bacia de captação. Esses três parâmetros morfométricos elementares possibilitaram a geração do mapa de energia do relevo para cada bacia de captação.

A técnica para a elaboração do mapa de dissecação vertical, desenvolvida por Spiridonov (1981), com adaptações de Mauro et al. (1985) e automatização de Ferreira (2015), permite mensurar a distância entre os talvegues e os divisores de água, possibilitanto a identificação do grau de entalhamento vertical desencadeado pelos processos geomorfológicos em climas úmidos (Boin et al., 2014). Para a elaboração dos mapas de dissecação vertical, Ferreira (2015) destaca que é necessária a inserção dos seguintes dados espaciais na interface do plugin: os polígonos das sub-bacias, os vetores em linha que representam os canais de drenagem, as curvas de nível e o modelo digital de elevação (MDE) - obtido através da união dos arquivos vetoriais referentes aos pontos cotados, curvas de nível, rede de drenagem e bacia hidrográfica, com a resolução de $15 \times 15 m$ - e informações referentes a equidistância das curvas de nível, que são de 20 metros, uma vez que a escala de trabalho adotada foi de 1:50.000.

Já o mapa de dissecação horizontal (que permite identificar a distância horizontal entre os divisores de água no interior de uma sub-bacia) foi obtido a partir da inserção 
dos seguintes dados na interface da ferramenta de Ferreira (2015): vetores correspondentes aos canais de drenagem, polígonos das sub-bacias e o modelo digital de elevação (MDE). Posteriormente, foi estabelecido o parâmetro de segmentação de drenagem, que é definido de acordo com a escala de trabalho adotada, e do erro gráfico tolerável para a pesquisa (que possui um erro gráfico de 10 metros, uma vez que a escala de trabalho é de 1:50.000), e o parâmetro de agrupamento de drenagem, que é definido de acordo com a sinuosidade apresentada pelo canal de drenagem, neste sentido, quanto mais sinuosos são os canais, maior será a quantidade de pontos criados pelo sistema (IBGE, 1999; Ferreira, 2015).

Os mapas de declividade de cada bacia de captação foram obtidos através da ferramenta Slope, presente em Spacial Analyst Tools, no software ArcGis 10.2., no qual foi adicionado à interface da ferramenta somente o modelo digital de elevação (MDE). Após a obtenção dos produtos, foi necessário realizar a reclassificação das classes de declividade, através da ferramenta Reclassify, na qual foram definidas seis classes de declividade (Tabela I), conforme Ferreira (2015), adaptado de Spera et al. (2004). Os mapas de declividade apresentam as classes em porcentagem.

Tabela I: Classes de declividade, conforme a aptidão agrícola do terreno.

\begin{tabular}{|c|c|c|}
\hline \multicolumn{2}{|c|}{ Declividade } & Relevo \\
\hline Classe & Porcentagem (\%) & Tipo \\
\hline A & $<3$ & Plano \\
\hline B & $3-8$ & Suave Ondulado \\
\hline C & $8-13$ & Moderadamente Ondulado \\
\hline D & $13-20$ & Ondulado \\
\hline E & $20-45$ & Forte Ondulado \\
\hline F & $>45$ & Montanhoso e Escarpado \\
\hline
\end{tabular}

Fonte: Adaptado de Spera et al. (2004).

Posteriormente, foi realizada a transformação dos produtos da declividade em formato raster para arquivo vetorial do tipo polígono, para o cruzamento com os arquivos referentes a dissecação vertical e a dissecação horizontal. Para esta operação foi utilizada a ferramenta Raster to Polygon. Após a transformação foram criados polígonos referentes a cada classe de declividade, que foram devidamente unidas através da ferramenta Merge.

Para a obtenção dos mapas de energia do relevo de cada bacia de captação foi necessária a união dos três produtos cartográficos anteriormente descritos: declividade, dissecação vertical e dissecação horizontal (Mendes, 1993; Ferreira, 2015).

Para isso foi realizada, primeiramente, a sobreposição destes arquivos vetoriais, através da ferramenta Intersect. Posteriormente é atribuída à tabela de atributos uma nova coluna do tipo 'text', nomeada como 'energia'. Nesta coluna foi realizado o cálculo da energia do relevo, a partir da peculiaridade de cada bacia de captação em 
análise: área $\left(\mathrm{km}^{2}\right)$, características altimétricas, geológicas, geomorfológicas e das condições da paisagem, refletidas nos parâmetros de declividade, dissecação vertical e horizontal, conforme o Tabela II.

Tabela II: Critérios estabelecidos para a geração do mapa de energia do relevo das bacias de captação das Cachoeiras Arco-Íris, Imigrante e Paraíso.

\begin{tabular}{|c|c|c|c|c|c|c|c|c|c|c|c|c|c|c|c|c|}
\hline \multicolumn{9}{|c|}{ BACIA DE CAPTAÇÃO DA CACHOEIRA ARCO-ÍRIS } & \multicolumn{8}{|c|}{ BACIA DE CAPTAÇÃO DA CACHOEIRA IMIGRANTE } \\
\hline $\begin{array}{l}\text { Classes de } \\
\text { energia do } \\
\text { relevo }\end{array}$ & $\begin{array}{c}\text { Declividade } \\
(\%)\end{array}$ & $\begin{array}{l}\frac{0}{0} \\
\frac{\pi}{0} \\
\frac{\pi}{0} \\
\text { ठ․ }\end{array}$ & $\begin{array}{c}\text { Dissecação } \\
\text { Horizonal } \\
(\mathrm{m})\end{array}$ & $\begin{array}{l}\overline{0} \\
\frac{0}{0} \\
\frac{\pi}{0} \\
o ̋ \\
0\end{array}$ & $\begin{array}{l}\text { Disse } \\
\text { Vertic }\end{array}$ & $\begin{array}{l}\text { ação } \\
\text { al }(m)\end{array}$ & $\begin{array}{r}\text { Ordem } \\
\text { classific }\end{array}$ & $\begin{array}{l}\text { de } \\
\text { ação }\end{array}$ & $\begin{array}{l}\text { Classes de } \\
\text { energia do } \\
\text { relevo }\end{array}$ & & $\begin{array}{l}\text { eclividade } \\
(\%)\end{array}$ & $\begin{array}{l}\frac{\overline{0}}{\%} \\
\frac{\pi}{0} \\
0\end{array}$ & \begin{tabular}{|c} 
Dissecação \\
Horizontal \\
$(\mathrm{m})$
\end{tabular} & 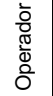 & $\begin{array}{l}\text { Dissecação } \\
\text { Vertical }(m)\end{array}$ & $\begin{array}{l}\text { Ordem de } \\
\text { classificação }\end{array}$ \\
\hline \multirow{2}{*}{ Muito Forte } & \multirow{2}{*}{$>45$} & \multirow{2}{*}{ OU } & \multirow{2}{*}{$<50$} & \multirow{2}{*}{ OU } & \multicolumn{2}{|c|}{$>100$} & \multirow{2}{*}{\multicolumn{2}{|c|}{1}} & \multirow{2}{*}{ Muito Forte } & \multirow{2}{*}{\multicolumn{2}{|c|}{$>45$}} & \multirow{2}{*}{ - } & \multirow{2}{*}{ - } & \multirow{2}{*}{ - } & \multirow{2}{*}{ - } & \multirow{2}{*}{1} \\
\hline & & & & & \multicolumn{2}{|c|}{$80-100$} & & & & & & & & & & \\
\hline Forte & $20-45$ & OU & $50-100$ & OU & $60-$ & & \multicolumn{2}{|l|}{2} & Forte & \multicolumn{2}{|r|}{$20-45$} & OU & $50-100$ & $\mathrm{E}$ & $>100$ & \multirow[b]{2}{*}{3} \\
\hline $\begin{array}{c}\text { Medianamente } \\
\text { Forte }\end{array}$ & $13-20$ & OU & $100-200$ & OU & $40-$ & & \multicolumn{2}{|l|}{3} & $\begin{array}{c}\text { Medianamente } \\
\text { Forte }\end{array}$ & \multicolumn{2}{|r|}{$13-20$} & OU & $100-200$ & OU & $80-100$ & \\
\hline Média & $8-13$ & OU & $200-400$ & $\mathrm{OU}$ & 20 & & \multicolumn{2}{|l|}{4} & Média & & $8-13$ & $\mathrm{OU}$ & $200-400$ & $\mathrm{OU}$ & $60-80$ & 4 \\
\hline Fraca & $3-8$ & $\mathrm{OU}$ & $400-800$ & $\mathrm{OU}$ & $<2$ & & 5 & & Fraca & & $3-8$ & $\mathrm{OU}$ & $400-800$ & $\mathrm{OU}$ & $60-80$ & 5 \\
\hline Muito Fraca & $<3$ & $\mathrm{OU}$ & - & $\mathrm{OU}$ & - & & 6 & & Muito Fraca & & $<3$ & $\mathrm{OU}$ & $>800$ & $\mathrm{OU}$ & $40-60$ & 6 \\
\hline & & & & & & BACIA & $A D E C A P$ & TAÇÃ & O DA CACHOE & EIRA & PARAÍSO & & & & & \\
\hline & & & & $\begin{array}{l}\text { asses } \\
\text { ergia } \\
\text { relevc }\end{array}$ & & Decli & $\begin{array}{l}\text { ividade } \\
\text { (\%) }\end{array}$ & $\begin{array}{l}\frac{1}{0} \\
\frac{\pi}{0} \\
\frac{0}{0} \\
0 \\
0\end{array}$ & $\begin{array}{c}\text { Dissecação } \\
\text { Horizontal } \\
(\mathrm{m})\end{array}$ & $\begin{array}{l}\frac{1}{0} \\
\frac{\pi}{0} \\
\frac{0}{0} \\
0\end{array}$ & $\begin{array}{c}\text { Dissecaçã } \\
\text { Vertical } \\
\text { (m) }\end{array}$ & & $\begin{array}{l}\text { Drdem de } \\
\text { lassificação }\end{array}$ & & & \\
\hline & & & & iito $\mathrm{Fc}$ & orte & & $>45$ & OU & $<50$ & OU & $>100$ & & 1 & & & \\
\hline & & & & Forte & & & $0-45$ & OU & $50-100$ & OU & $80-100$ & & 2 & & & \\
\hline & & & Medi & $\begin{array}{l}\text { ianam } \\
\text { Forte }\end{array}$ & nente & & $3-20$ & OU & $100-200$ & OU & $60-80$ & & 3 & & & \\
\hline & & & & Médi & & & 8-13 & OU & $200-400$ & OU & $40-60$ & & 4 & & & \\
\hline & & & & Fraca & & & $3-8$ & $\mathrm{OU}$ & $>400$ & OU & $20-40$ & & 5 & & & \\
\hline & & & Mui & iito $\mathrm{Fr}$ & aca & & $<3$ & $\mathrm{OU}$ & - & OU & $<20$ & & 6 & & & \\
\hline
\end{tabular}

Fonte: Autores.

Após a obtenção dos quadros sínteses, foram realizadas as adequações dos códigos de programação em linguagem Python, e a aplicação dos mesmos a partir da ferramenta Field Calculator, presente na coluna 'energia'. Na interface da ferramenta foram inseridos os dados de programação em Python. Por fim, foi realizada a reclassificação dos polígonos e das classes de energia do relevo, conforme destacado na Tabela III.

Tabela III: Classes de Energia do Relevo

\begin{tabular}{|c|c|c|}
\hline$N^{\circ}$ da Classe & Casse de energia do relevo & RGB \\
\hline 1 & Muito Forte & R: 115 G: 38 B:0 \\
\hline 2 & Forte & R: 230 G: 0 B:0 \\
\hline 3 & Medianamente Forte & R:255 G:150 B:0 \\
\hline 4 & Média & R:255 G:255 B:0 \\
\hline 5 & Fraca & R: 76 G:115 B:0 \\
\hline 6 & Muito Fraca & R: 112 G:168 B:0 \\
\hline
\end{tabular}

Fonte: Adapatado de Ferreira (2015). 


\section{Resultados e Discussões}

A aplicação dos procedimentos metodológicos às bacias de captação das cachoeiras selecionadas permitiu constatar que a bacia de captação da cachoeira Arco-Íris apresentou o maior índice de circularidade $(0,55)$. Esta conjuntura favorece os processos de inundação que podem ter consequência direta na cachoeira utilizada para práticas de lazer e turismo, bem como sobre as estruturas que foram consolidadas para a recepção de turistas nos meses de verão. A bacia de captação da cachoeira Imigrante obteve um índice de circularidade (Ic) de 0,38 caracterizandose como uma bacia alongada, com baixa propensão a inundações, enquanto a bacia de captação da cachoeira Paraíso apresentou índice de circularidade (Ic) de 0,46, também indicando formato alongado, não contribuindo para a concentração de água e desenvolvimento de processos de inundação.

No que se refere à densidade hidrográfica $(\mathrm{Dh})$, verificou-se que a bacia de captação da cachoeira Arco-Íris apresentou um valor de 3,22 canais $/ \mathrm{km}^{2}$, que confere à mesma média capacidade em gerar novos cursos d'água, uma vez que os valores podem variar de $<3$ canais $/ \mathrm{km}^{2}$ (para bacias hidrográficas de baixa capacidade) a $>15$ canais $/ \mathrm{km}^{2}$ (para bacias hidrográficas com alta capacidade) (Santos et al., 2012). A bacia de captação da cachoeira Imigrante exibiu uma densidade hidrográfica (Dh) de 2,93 canais $/ \mathrm{km}^{2}$, constatando que a mesma possui baixa capacidade de gerar novos cursos d'água. Já a bacia de captação da cachoeira Paraíso obteve 5,16 canais $/ \mathrm{km}^{2}$, possuindo o maior índice de densidade hidrográfica $(\mathrm{Dh})$.

No que diz respeito à densidade de drenagem (Dd), a bacia de captação da cachoeira Arco-Íris apresentou um valor de $2,76 \mathrm{~km} / \mathrm{km}^{2}$, considerado por Beltrame (1994, apud Santos et al., 2012) como um valor alto, uma vez que o mesmo varia de $<0,50 \mathrm{~km} / \mathrm{km}^{2}$ para densidades de drenagem baixas a $>3,50$ para áreas de valores muito altos. As bacias de captação da cachoeira Imigrante e Paraíso apresentaram uma densidade de drenagem (Dd) de $2,49 \mathrm{~km} / \mathrm{km}^{2}$ e $3,44 \mathrm{~km} / \mathrm{km}^{2}$ respectivamente. Constata-se, neste sentido, que as três bacias hidrográficas possuem pouca infiltração, possibilitando uma maior capacidade em gerar novos cursos d'água. Tal situação reflete os aspectos geológicos das áreas de estudo, assentadas sobre rochas graníticas, predominantemente. Tanto os resultados de densidade hidrográfica como densidade de drenagem verificados favorecem a manutenção da integridade ambiental e vazão das cachoeiras selecionadas para esta análise, configurando-se como aspectos positivos para as práticas de lazer e turismo nestes locais.

A avaliação da energia do relevo nas bacias de captação indicou que a bacia de captação da cachoeira Arco-Íris apresenta uma área de aproximadamente 92\% (9,13 $\mathrm{km}^{2}$ ) ocupada por classes de elevada energia do relevo (muito forte, forte e medianamente forte) (Figura 3).

Dentre estas classes de elevada energia do relevo, cabe destaque para a classe medianamente forte, que apresentou o percentual de $58 \%\left(5,79 \mathrm{~km}^{2}\right)$ da área da bacia de captação da cachoeira Arco-íris. A classe medianamente forte é oriunda, 
principalmente, dos parâmetros de dissecação horizontal (100-200m), e de declividade (13-20\%).

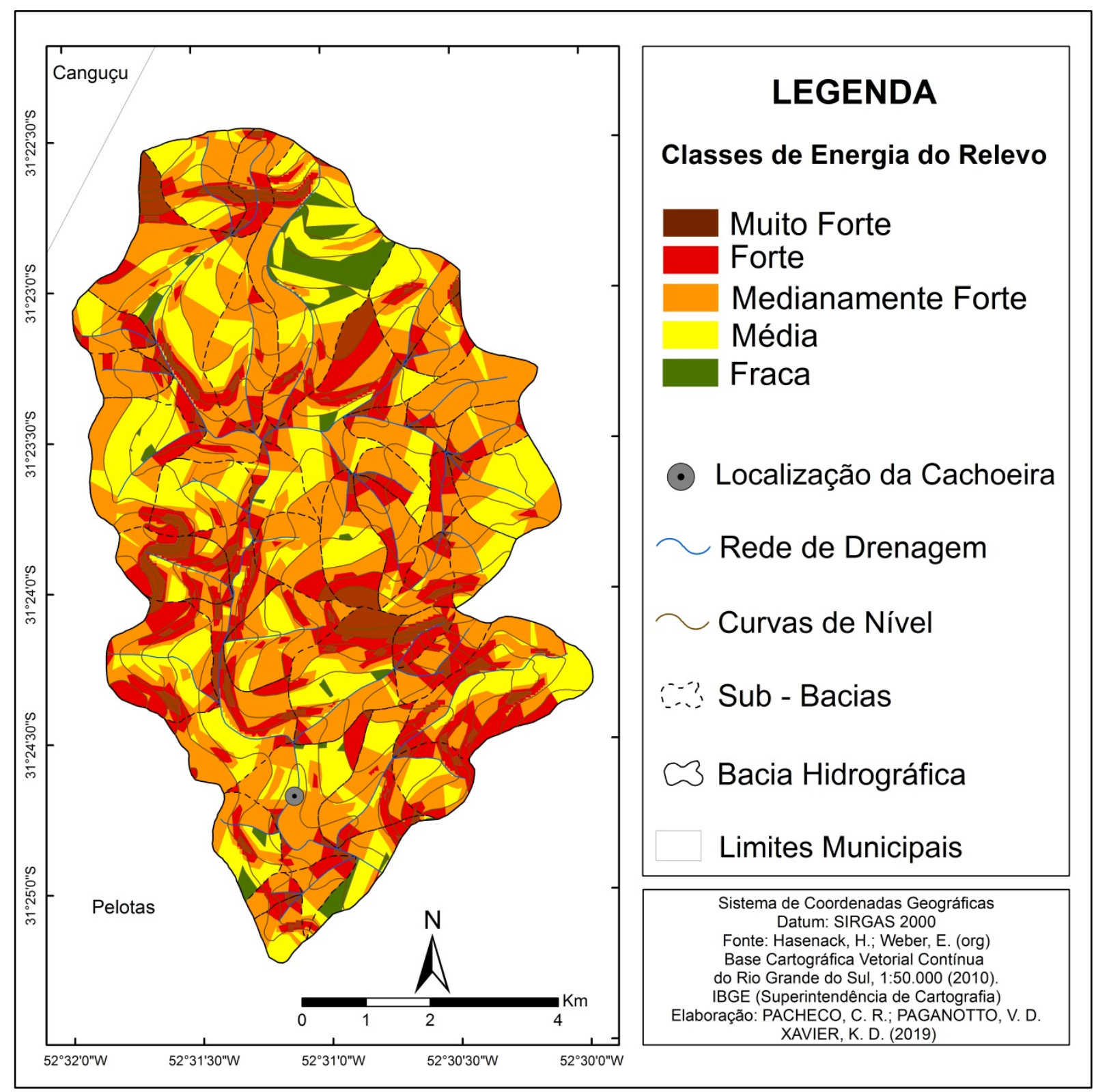

Figura 3: Mapa de energia do relevo da bacia de captação da cachoeira Arco-Íris.

Fonte: Autores.

A classe forte ocorre em cerca de $21 \%\left(2,09 \mathrm{~km}^{2}\right)$ da bacia de captação da cachoeira Arco-Íris. Esta classe é fortemente induzida pela dissecação horizontal (50 - 100m), que se encontra presente predominantemente nas áreas de união de canais de drenagem de primeira ordem, em associação com declividades que variam de 20 $45 \%$, e em superfícies com dissecações verticais que variam de $60-30 \mathrm{~m}$.

A classe muito forte foi verificada em aproximadamente $13 \%\left(1,25 \mathrm{~km}^{2}\right)$ da bacia de captação da cachoeira Arco-Íris e é resultante, predominantemente, da relação entre parâmetros de dissecação vertical que apresentam valores menores que $100 \mathrm{~m}$ e de 
80-100m, localizados em pontos específicos de maior altitude e com declividades superiores a $45 \%$.

A classe de energia do relevo fraca diz respeito a aproximadamente $6 \%\left(0,56 \mathrm{~km}^{2}\right) \mathrm{da}$ bacia de captação da cachoeira Arco-Íris e configura-se por meio da relação das dissecações horizontais que variam de 400-800m e da dissecação vertical, com valores inferiores a $20 \mathrm{~m}$. Por fim, os valores de média energia do relevo, que representa $2 \%\left(0,21 \mathrm{~km}^{2}\right)$ da área de estudo são oriundos predominantemente da união dos dados de dissecação vertical, com valores que variam no intervalo de 2040m e da dissecação horizontal, de 200-400m.

O predomínio de superfícies com elevadas energias do relevo na bacia de captação da cachoeira Arco-Íris qualifica a mesma como uma bacia com alta propensão aos processos morfogenéticos. Esse quadro também se torna crítico quando associado à ocorrência de precipitações extremas, uma vez que a área de estudo também exibiu um elevado índice de circularidade (Ic), com o valor de 0,55. Cabe, nesse sentido, um monitoramento e preservação das práticas de uso da terra e a proteção das áreas de preservação permanente (APP's) na bacia de captação, a fim de evitar que estas propensões naturais tenham efeito sobre a integridade ambiental da cachoeira do Arco-Íris.

A bacia de captação da cachoeira Imigrante apresentou $48 \%$ da sua área sob ocorrência de elevadas energias do relevo, compreendidas pelas classes muito forte, forte e medianamente forte (Figura 4). Dentre elas, a classe medianamente forte ocorre em aproximadamente $35 \%\left(18,47 \mathrm{~km}^{2}\right)$ da área total, sendo a classe com maior ocorrência ao longo da bacia, resultante de dissecações horizontais entre 100-200m, dissecações verticais entre 80-100m e declividades de 13-20\%.

A classe de energia do relevo média apresentou a segunda maior área com 13,47 km² (25\%) ocorrendo em locais onde coexistem os parâmetros de dissecação horizontal entre $200-400 \mathrm{~m}$, dissecação vertical entre $60-80 \mathrm{~m}$ e declividades de $8-13 \%$. Na sequência aparecem as classes fraca com $22 \%\left(11,62 \mathrm{~km}^{2}\right)$, forte com $11 \%\left(5,75 \mathrm{~km}^{2}\right)$ e muito fraca com $5 \%\left(2,68 \mathrm{~km}^{2}\right)$ de área ocupada. A classe fraca ocorre onde existem associações de dissecação horizontal entre 400-800m, dissecação vertical de 60-80m e declividade de 3-8\%. A classe forte ocorre onde coexistem dissecações horizontais entre $50-100 \mathrm{~m}$, dissecação vertical maiores que $100 \mathrm{~m}$ e declividades entre $30-45 \%$ e a classe muito fraca ocorre sob dissecações horizontais maiores que $800 \mathrm{~m}$, dissecações verticais entre 40-60m e de declividades menores que $3 \%$.

A classe de energia muito forte corresponde a aproximadamente $2 \%$ da bacia de captação da cachoeira Imigrante, sendo a classe menos expressiva, ocorrendo em áreas de elevadas altitudes associadas às declividades superiores a 45\%. Nessas áreas são desaconselhados quaisquer tipos de atividades antrópicas, por serem terrenos que apresentam grande suscetibilidade a processos morfogenéticos e erosivos. 


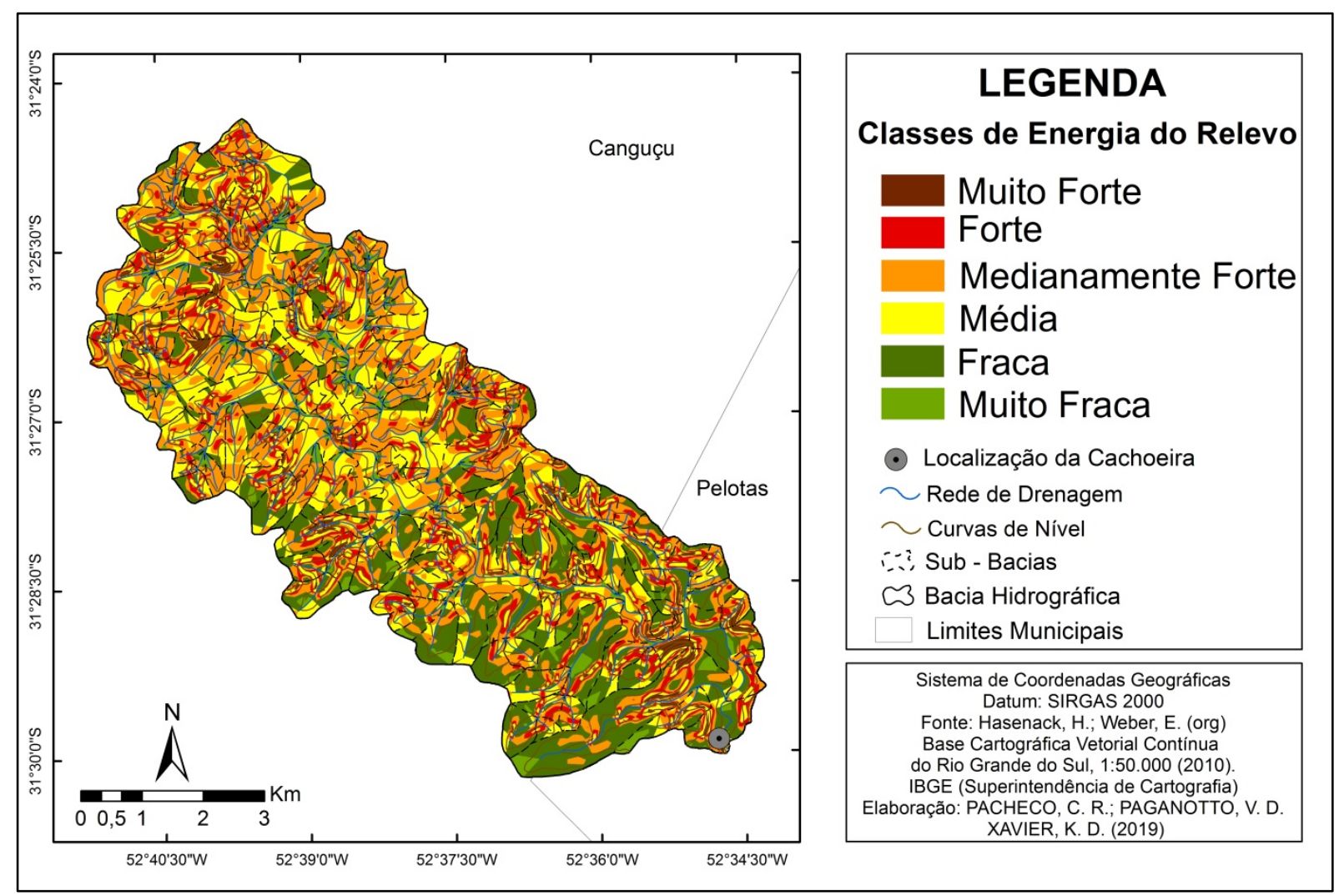

Figura 4: Mapa de energia do relevo da bacia de captação da cachoeira Imigrante.

Fonte: Autores.

A análise dos dados morfométricos da bacia de captação da cachoeira Imigrante possibilitou identificar setores potencialmente propensos a processos erosivos como erosão laminar, surgimento de sulcos e ravinas e deslizamentos. Mesmo na área apresentando, em geral, energia de relevo média a medianamente forte, a presença de práticas de cultivo utilizadas de forma incorreta e em áreas inadequadas pode acarretar grandes degradações ambientais. Por apresentar a maior área dentre as bacias de captação das três cachoeiras analisadas, a bacia de captação da cachoeira Imigrante possui uma diversidade de usos da terra voltados às práticas agrícolas que nem sempre respeitam as condições geomorfológicas e a legislação ambiental. $O$ monitoramento destas práticas e conflitos também se torna mais desafiador. Entretanto, deve ocorrer para que as condições atuais da cachoeira não sejam ameaçadas pela quantidade e qualidade de material que pode ser remobilizado até o canal principal e ser depositado ao longo da cachoeira e seus poços, comprometendo seu aproveitamento turístico.

A bacia de captação da cachoeira Paraíso possui aproximadamente $69 \%\left(10,72 \mathrm{~km}^{2}\right)$ de classes de elevada energia do relevo, compreendida pelas classes muito forte, forte e medianamente forte (Figura 5).

A classe medianamente forte representa $43 \%\left(6,71 \mathrm{~km}^{2}\right)$ da área total da bacia de captação da cachoeira Paraíso e é oriunda da organização espacial da dissecação horizontal situada entre 100-200 m. A classe de energia do relevo forte ocorre em cerca de $21 \%\left(3,21 \mathrm{~km}^{2}\right)$ da bacia de captação da cachoeira Paraíso, sendo resultante 
da combinação das classes de dissecação horizontal entre 50-100 m e 100-200m, que se encontram, principalmente, no entorno dos canais fluviais de primeira ordem, e da declividade de $20-45 \%$.

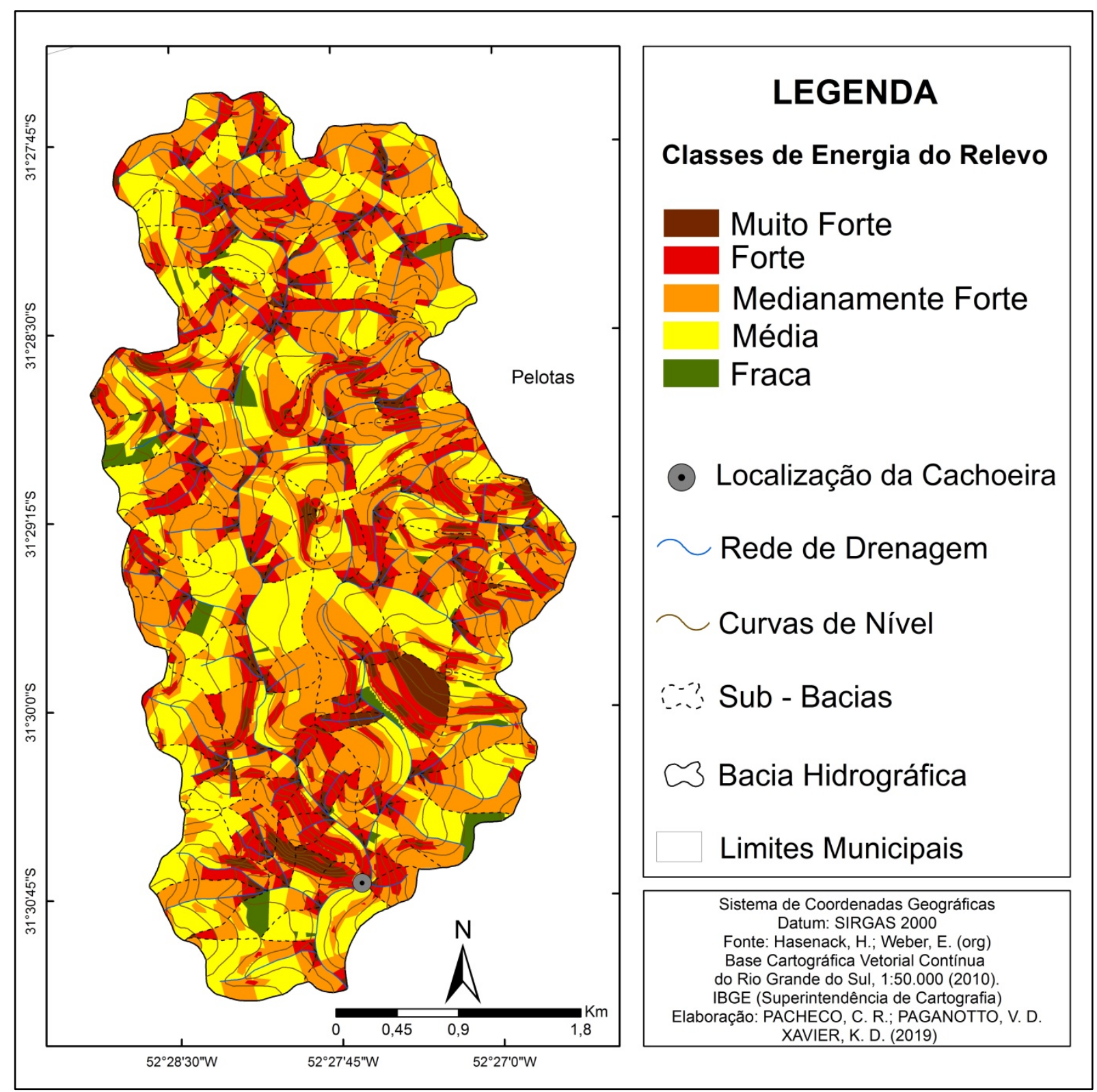

Figura 5: Mapa de Energia do Relevo da bacia de captação da cachoeira Paraíso.

Fonte: Autores.

A classe de energia muito forte diz respeito a $5 \%\left(0,80 \mathrm{~km}^{2}\right)$ da área total da bacia de captação da cachoeira Paraíso e é resultante da articulação espacial da classe de dissecação vertical menor que $100 \mathrm{~m}$, da classe de declividade com valores maiores que $45 \%$ e da classe de dissecação horizontal com valores menores que $50 \mathrm{~m}$. Destaca-se que a energia muito forte encontra-se predominantemente na confluência dos canais fluviais e próximo à cachoeira. 
A classe de energia do relevo média ocorre em $29 \%\left(4,53 \mathrm{~km}^{2}\right)$ da área total da bacia de captação da cachoeira Paraíso, sendo oriunda, basicamente, da classe de dissecação horizontal entre $200-400 \mathrm{~m}$. A classe de energia fraca diz respeito a cerca de $2 \%\left(0,31 \mathrm{~km}^{2}\right)$ da bacia de captação da cachoeira Paraíso resultante da dissecação horizontal, encontra-se em porções isoladas ao longo da bacia, geralmente em contato com as áreas de energia média.

A bacia de captação da cachoeira Paraíso possui valores de densidade de drenagem e densidade hidrográfica que possibilitam a geração de novos cursos d'água, podendo estar relacionadas com as características das rochas graníticas. Também é possível verificar, a partir da análise da energia do relevo, quais as áreas estão propicias aos eventos erosivos que atuam diretamente na morfodinâmica da bacia de captação e da cachoeira Paraíso. Neste sentido, se fazem necessárias ações de geoconservação na bacia de captação e na cachoeira.

Pode-se observar na Tabela IV os resultados das três bacias de captação, obtidos a partir da elaboração dos mapas de energia do relevo, com destaque para as duas classes que possuem predominância em cada bacia de captação, em km².

Tabela IV: Resultados obtidos através da aplicação da metodologia de energia do relevo.

\begin{tabular}{|c|c|c|c|c|c|c|}
\hline \multirow{2}{*}{ Classe de Energia do Relevo } & \multicolumn{2}{|c|}{ ARCO-ÍRIS } & \multicolumn{2}{c|}{ IMIGRANTE } & \multicolumn{2}{c|}{ PARAÍsO } \\
\cline { 2 - 7 } & Área $\left(\mathrm{km}^{2}\right)$ & Área $(\%)$ & Área $\left(\mathrm{km}^{2}\right)$ & Área (\%) & Área $\left(\mathrm{km}^{2}\right)$ & Área (\%) \\
\hline Muito Forte & 1,25 & $13 \%$ & 1,04 & $2 \%$ & 0,80 & $5 \%$ \\
\hline Forte & 2,09 & $21 \%$ & 5,75 & $11 \%$ & 3,21 & $21 \%$ \\
\hline Medianamente Forte & 5,79 & $58 \%$ & 18,47 & $35 \%$ & 6,71 & $43 \%$ \\
\hline Média & 0,21 & $2 \%$ & 13,47 & $25 \%$ & 4,53 & $29 \%$ \\
\hline Fraca & 0,56 & $6 \%$ & 11,62 & $22 \%$ & 0,31 & $2 \%$ \\
\hline Muito Fraca & - & - & 2,68 & $5 \%$ & - & - \\
\hline & 9,90 & $100 \%$ & 53,03 & $100 \%$ & 15,55 & $100 \%$ \\
\hline
\end{tabular}

Fonte: Autores.

\section{Conclusões}

A partir dos resultados obtidos constatou-se que a cachoeira Arco-Íris apresenta os maiores resultados em relação ao índice de circularidade (Ic) e de áreas com elevada energia do relevo (classes muito forte, forte e medianamente forte). $O$ índice de circularidade apresentado pela mesma é de 0,55 , indicando que a bacia de captação favorece os processos de inundação ocorridos em períodos de extremos pluviométricos, ocasionando perdas de matéria orgânica e de nutrientes presentes nos solos, acarretando em processos de erosão, principalmente, quando estes não possuem cobertura vegetal.

As áreas de elevada energia do relevo, que dizem respeito a $92 \%$ da área total da bacia de captação da cachoeira Arco-Íris, favorecem a ocorrência de processos morfogenéticos e gravitacionais do solo. Mesmo sendo um processo natural, ele 
podem ser intensificados pelas ações antropogênicas que se dão no interior da bacia hidrográfica, influenciando na carga de sedimentos transportados pelos cursos d'água e que se refletem no nível de base da área de estudo, a cachoeira Arco-Íris, constituindo bancos de areia no poço da cachoeira e influenciando na atratividade turística e estética que a mesma possui.

A bacia de captação da cachoeira Imigrante possui a maior área dentre as três bacias estudadas $\left(53,03 \mathrm{~km}^{2}\right)$. Entretanto, apresenta o menor resultado de índice de circularidade, com 0,38 . Essa conjuntura evidencia que a área tende a ser mais alongada e com menor probabilidade de cheias. Esta bacia hidrográfica também possui o menor valor de densidade hidrográfica (Dh), indicando que esta bacia de captação tem pouca aptidão em gerar novos cursos d'água. Tais resultados, em conflito com práticas de uso da terra conflituantes, podem contribuir para perdas das características geopatrimôniais da cachoeira Imigrante.

Quanto aos resultados de energia do relevo, a bacia hidrográfica em questão possui o menor percentual de elevadas energias do relevo, com $48 \%$ da área total da área pesquisada. Este resultado é influenciado predominantemente pelas declividades e pela dissecação horizontal, que se exibem na alta e na média bacia da área de estudo e acarretam na distribuição dos sedimentos ao longo dos cursos d'água e o assoreamento da rede de drenagem.

A bacia de captação da cachoeira Paraíso possui o maior índice de densidade hidrográfica dentre as três bacias hidrográficas em análise, com 5,16 canais $/ \mathrm{km}^{2}$, que possibilita a maior probabilidade da bacia hidrográfica em gerar novos cursos d'água. Quanto aos resultados obtidos pela aplicação da técnica de energia do relevo, a bacia de captação da cachoeira Paraíso, destaca-se por apresentar $69 \%$ de classes de elevada energia do relevo, as quais se encontram em predominância nas confluências dos canais fluviais, com maior influência dos parâmetros de dissecação horizontal e declividade, e com influência da dissecação vertical nas proximidades da cachoeira.

Neste contexto, se fazem necessárias ações de geoconservação pautadas no planejamento da dinâmica de uso e ocupação das terras, tendo em vista que as bacias de captação em estudo localizam-se em áreas rurais e que todos os processos antropogênicos influenciarão na integridade ambiental das cachoeiras. Destaca-se, que a bacia de captação da cachoeira Arco-Íris apresenta maior suscetibilidade aos processos erosivos, que compromete a integridade ambiental da mesma, tornandose prioritária para este tipo de ação proposta. Salienta-se também que se fazem necessários estudos sobre o uso e ocupação das terras para serem confrontados com os dados de energia do relevo, possibilitando a identificação de áreas adequadas e inadequadas a ocupação espacial, subsidiando estratégias de geoconservação.

\section{Agradecimentos}

Agradecemos à Pró-Reitoria de Extensão e Cultura da Universidade Federal de Pelotas, pelo apoio ao projeto "Entre Águas e Rochas: diagnóstico ambiental das quedas de água do município de Pelotas (RS) com ênfase na geoconservação". 


\section{Bibliografia}

Bento, L. C. M., Rodrigues, S. C. (2010). Geoturismo e geomorfossítios: refletindo sobre o potencial turístico de quedas d'água-um estudo de caso do município de Indianópolis/MG. Revista Geografica Academica, 4(2), 96-104. Disponível em: https://revista.ufrr.br/rga/issue/view/181

Boin, M. N., Zanatta, F. A. S., Cunha, C. M. L. (2014). Avaliação da Morfometria do Relevo da Alta Bacia Hidrográfica do Ribeirão do Areia Dourada, Marabá Paulista (SP). Caderno Prudentino de Geografia, 2(36), 5-26. Disponível em: http://revista.fct.unesp.br/index.php/cpg/article/view/2866

Borba, A. W. (2011). Geodiversidade e geopatrimônio como bases para estratégias de geoconservação: conceitos, abordagens, métodos de avaliação e aplicabilidade no contexto do Estado do Rio Grande do Sul. Pesquisas em Geociências, 38(1), 3-13. https://doi.org/10.22456/1807-9806.23832

Brilha, J. B. (2005). Património Geológico e Geoconservação: a Conservação da Natureza na sua Vertente Geológica. Palimage Editores.

CPRM - Serviço Geológico do Brasil. Carta Geológica (2019). Programa Gestão Estratégica da Geologia, da Mineração e da Transformação Mineral. Folha Pelotas, SH.22-Y-D-IV. 1 mapa. Escala 1:100.000.

Cunha, C. M. L., Pinton, L. G. (2013). A cartografia do relevo como subsídio para a análise morfogenética de setor cuestiforme (the relief's cartography as subsidy for the morphogenetic analysis of cuestiform sector). Mercator, 12(27) 149-158. https://doi.org/10.4215/RM2013.1227.0011

Spera, S. T., Reatto, A., Martins, E. D. S., Farias, M. F. R., Silva, A. V. (2004). Aptidão agrícola das terras da bacia hidrográfica do Ribeirão Taguatinga, Distrito Federal. Embrapa Cerrados: Boletim de Pesquisa e Desenvolvimento (INFOTECA-E). Disponível em: https://www.embrapa.br/busca-de-publicacoes/-/publicacao/569094/aptidao-agricola-dasterras-da-bacia-hidrografica-do-ribeirao-taguatinga-distrito-federal

Ferreira, M. V. (2015). Contribuição metodológica ao estudo da dissecação e energia do relevo: proposta e avaliação de técnicas computacionais. Tese de Doutorado. Universidade Estadual Paulista, Instituto de Geociências e Ciências Exatas. Disponível em: https://repositorio.unesp.br/handle/11449/138513

Gray, M. (2004). Geodiversity: valuing and conserving abiotic nature. John Wiley \& Sons.

Hasenack, H., Weber, E. (2010). Base cartográfica vetorial contínua do Rio Grande do Sul escala 1: 50.000. UFRGS Centro de Ecologia, Porto Alegre, v. 1.

IBGE - Instituto Brasileiro de Geografia e Estatística (1999). Noções Básicas de Cartografia. Manuais Técnicos em Geociências. Rio de Janeiro: IBGE.

Jorge, M. C. O., Guerra, A. J. T. (2016). Geodiversidade, geoturismo e geoconservação: conceitos, teorias e métodos. Espaço Aberto, 6(1), 151-174. https://doi.org/10.36403/espacoaberto.2016.5241

Lana, C. E., Alves, J. M. P., Castro, P. T. A. (2001). Análise morfométrica da bacia do Rio Tanque, MG - Brasil. Revista Escola de Minas (Ouro Preto), 54(2). http://dx.doi.org/10.1590/S0370-44672001000200008 
Mauro, A. C., Mendes, I. A., Christofoletti (1985). A Implantação de estações geomorfológicas de observações: o projeto do IGCE-UNESP. Boletim de Geografia Teorética (Rio Claro), 15(29/30), 317-324.

Mendes, I. A. (1993). A dinâmica erosiva do escoamento pluvial na bacia do Córrego LafonAraçatuba-SP. Tese de Doutorado em Geografia Física. Faculdade de Filosofia Letras e Ciências Humanas, Universidade de São Paulo, São Paulo.

Rodrigues, M. L.; Fonseca, A. (2008). A valorização do geopatrimónio no desenvolvimento sustentável de áreas rurais. In: Actas do VII Colóquio Ibérico de Estudos Rurais, Coimbra. Disponível em: http://www.sper.pt/oldsite/actas7cier/PFD/Tema\%20II/2 14.pdf

Santos, A. M., Targa, M. B., Batista, G. T., Dias, N. W. (2012). Análise morfométrica das subbacias hidrográficas Perdizes e Fojo no município de Campos do Jordão, SP, Brasil. Ambiente \& Água - An Interdisciplinary Journal of Applied Science, 7(3), 195-211. http://dx.doi.org/10.4136/ambi-agua.945

Sharples, C. (2002). Concepts and principles of geoconservation. Tasmanian Parks and Wildlife Service.

Silva, J. F. A., Aquino, C. M. S. (2018). Ações geoeducativas para divulgação e valorização da geodiversidade e do geopatrimônio. GeoSaberes, 9(17), 1-12. https://doi.org/10.26895/geosaberes.v9i17.617

Spanghero, P. E. S. F., Meliani, P. F., Mendes, J. S. (2015). Mapeamento hidrográfico de detalhe e análise morfométrica comparativa das bacias dos rios Tijuípe e Tijupinho, litoral sul da Bahia. Caminhos da Geografia, 16(53), 101-117. Disponível em: http://www.seer.ufu.br/index.php/caminhosdegeografia/article/view/27861

Spiridonov, A. I. (1981). Principios de La Metodología de Las Investigaciones de Campo y el Mapeo Geomorfológico. Tradução de Isabel Alvarez e Roberto Del Busto. Havana: Universidad de la Habana, v. 3.

Teodoro, V. L. I., Teixeira, D., Costa, D. J. L., Fuller, B. B. (2007). O conceito de bacia hidrográfica e a importância da caracterização morfométrica para o entendimento da dinâmica ambiental local. Revista Brasileira Multidisciplinar, 11(1), 137-156. https://doi.org/10.25061/2527-2675/ReBraM/2007.v11i1.236

Von Ahn, M. (2018). Análise Antropogeomorfológica em Geossítio da história da mineração: estudo nas Minas do Camaquã - RS. Dissertação de Mestrado em Geografia. Programa de Pós-Graduação em Geografia, Instituto de Ciências Humanas, Universidade Federal de Pelotas.

Artigo recebido em/ Received on: 13/11/2019

Artigo aceite para publicação em/ Accepted for publication on: 29/12/2019 